\title{
QUICK CYTOGENETIC SCREENING OF BREEDING BULLS USING FLOW CYTOMETRIC SPERM DNA HISTOGRAM ANALYSIS
}

\author{
Szabolcs NAGY ${ }^{1 *}$, Péter J. PolgÁR ${ }^{1}$, Magnus Andersson ${ }^{2}$ and András KovÁCs ${ }^{3}$ \\ ${ }^{1}$ Department of Animal Sciences and Animal Husbandry, Georgikon Faculty, University \\ of Pannonia, Deák F. u. 16, H-8360 Keszthely, Hungary; ${ }^{2}$ Department of Production \\ Animal Medicine, Faculty of Veterinary Medicine, University of Helsinki, Saari Unit, \\ Saarentaus, Finland; ${ }^{3}$ Institute of Animal Science, Biotechnology and Nature Conservation, \\ Faculty of Agricultural and Food Sciences and Environmental Management, \\ University of Debrecen, Debrecen, Hungary
}

(Received 7 December 2015; accepted 4 May 2016)

The aim of the present study was to test the FXCycle PI/RNase kit for routine DNA analyses in order to detect breeding bulls and/or insemination doses carrying cytogenetic aberrations. In a series of experiments we first established basic DNA histogram parameters of cytogenetically healthy breeding bulls by measuring the intraspecific genome size variation of three animals, then we compared the histogram profiles of bulls carrying cytogenetic defects to the baseline values. With the exception of one case the test was able to identify bulls with cytogenetic defects. Therefore, we conclude that the assay could be incorporated into the laboratory routine where flow cytometry is applied for semen quality control.

Key words: Cytogenetics, translocation, sperm, flow cytometry

According to Amann and Hammerstedt (1993), the fertilising spermatozoon has to have a series of attributes in order to achieve its goal: acceptable morphology, proper metabolism for energy production, progressive motility, capacity for hyperactive motility, etc. In addition, the genetic package of the fertilising spermatozoon must contain genes needed for development and lack lethal mutations or extra genetic material preventing development. It can be hypothesised that the higher the proportion of motile, viable, morphologically normal spermatozoa with intact chromatin in the insemination dose, the better the chances for pregnancy (Morrell and Rodriguez-Martinez, 2009). Although motility and viability (and less frequently morphology) are routinely assessed in AI stations, the status of the genetic material is rarely tested.

The status of the paternal genome can be viewed at three stages: besides the increasing focus on genomic selection of breeding males (Amann and DeJarnette, 2012), the intactness of the chromatin and the haploid set of chromosomes

*Corresponding author; E-mail: nagy.szabolcs@georgikon.hu; Phone: 0036 (83) 545-349 
in the spermatozoon are different levels where we can assess the abovementioned status. The organisation of the sperm chromatin is unique, as histone proteins are eventually replaced by transition proteins and finally by protamines, resulting in an extremely compact, condensed DNA (Dadoune, 1995; Sakkas et al., 1999). Proper condensation may stabilise the DNA and makes it less sensitive to oxidative damage; however, mature spermatozoa are not able to repair DNA damage. Abnormalities of the sperm chromatin structure can cause disturbances in fertility, pronuclear formation, early embryo quality and pregnancy outcome. These abnormalities are classified as 'uncompensable', as subfertile males cannot be brought to normal fertility by increasing the inseminate dosage. Sperm cells with uncompensable defects are able to fertilise oocytes; however, embryo development may be abnormal (Evenson, 1999).

The problem with paternal chromosomes can be viewed at two levels: (a) structural (i.e. translocations, deletions, duplications, etc.), and (b) numerical (alterations in the normal, haploid chromosome numbers).

Since the 1960s, animal cytogenetics has become more and more important (Ducos et al., 2008). The cytogenetic quality of breeding bulls and boars has great economic importance (Larsen et al., 2004). Classic techniques to detect abnormal karyotypes are based on microscopic analysis of peripheral blood lymphocytes (Matsson et al., 1986). Microscopic countings, however, are time consuming and require specialised expertise. Flow cytometry offers a more precise and quick alternative, and it was successfully applied in karyotyping of several mammalian species including sheep, cattle, pig (Dixon et al., 1992), dog (Langford et al., 1996) and human (van den Engh et al., 1985). Flow karyotyping has not become a routine evaluation for domestic animals as the technique is rather difficult and the resolution of bivariate flow karyograms is usually not perfect, i.e. the smaller chromosomes are not distinguishable. Moreover, individual chromosome polymorphisms can result in differing flow karyotypes between healthy individuals. The sensitivity of the technique stands between that of traditional light microscopic chromosome banding and flow cytometric assessment of the total DNA content of whole cells (Givan, 2001).

Flow cytometry offers a tool to measure the total DNA content of sperm cells (Lewalski et al., 1991), which has several advantages, like no need to collect blood and the possibility of monitoring transported semen without actually meeting the animal in question. Translocation carriers were successfully detected by flow cytometry (Lewalski et al., 1991, 1993). The flow cytometric DNA content analysis of spermatozoa has led to the successful separation of X- and Ychromosome bearing germ cells (Gledhill et al., 1976; Meistrich et al., 1978). The unique paddle-like shape of the mammalian spermatozoon, however, is a great technical challenge, and special hydrodynamic cell orientation is needed to ensure that every spermatozoon will have the same orientation allowing the fluorescence measurement of the flat surface of the cells (Garner, 2001). In our pre- 
vious studies (Revay et al., 2009, 2010) our flow cytometric analyses revealed spermatozoa with abnormal chromosomal content and incomplete chromatin condensation.

To overcome the need of a sophisticated flow cytometer equipped with a sperm head orienting device, Larsen et al. (2004) developed a simplified approach for the detection of males with spermatozoa carrying cytogenetic aberrations. They applied a series of enzymatic and chemical treatments for sperm head decondensation to have swollen and rounded sperm nuclei, eliminating the need of sperm orientation. They developed a model for normality of the sperm DNA histograms: two subpopulations (i.e. X- and Y-chromosome bearing germ cells) and histogram CV equal to or less than $1.3 \%$. They stated, however, that their protocol was unfeasible in its current form for routine screening purposes. They suggested several critical points for the improvement; however, these have not been carried out so far.

Recently, relatively cheap and easy-to-use benchtop flow cytometers have become available even for the use in routine AI centres for daily semen quality control (Hossain et al., 2011). Most of these instruments are, however, equipped with a $488 \mathrm{~nm}$ laser which is not suitable for the DNA-specific fluorochromes used in sperm sexing and other quantitative DNA analyses, namely the Hoechst dyes and 4'6-diamidino-2-phenylindole (DAPI) stain.

The aim of the present study was to test another fluorochrome which is properly excited with the $488 \mathrm{~nm}$ laser line and therefore would be suitable for routine DNA analyses aiming to detect breeding males and/or insemination doses carrying cytogenetic aberrations. In a series of experiments we first established basic DNA histogram parameters of cytogenetically healthy breeding bulls by measuring the intraspecific genome size variation of three animals (each of them three times - as suggested by Dolezel and Bartos, 2005), then we compared the histogram profiles of bulls carrying cytogenetic defects to the baseline values.

\section{Materials and methods}

\section{Semen samples}

In Experiment 1 we used frozen-thawed semen samples from three bulls free from cytogenetic defects. In Experiment 2 one of the bulls from Experiment 1 was used as control (bull A) and bulls with the following cytogenetic aberrations were tested: bull B was a carrier of 2;4 reciprocal translocation (Switonski et al., 2008); bull C was a carrier of 20;24 reciprocal translocation (Andersson et al., 1992); bull D produced approximately 20-25\% diploid spermatozoa (Revay et al., 2010); bull E had a translocation between chromosomes 6 and 29 (Venhoranta et al., 2013). 


\section{DNA labelling}

Sperm DNA was labelled with propidium iodide (PI) as part of the FXCycle PI/RNase kit (F10797, Molecular Probes).

Labelling followed the protocol suggested by the manufacturer: spermatozoa were fixed in $70 \%$ ethanol, then washed from the fixative (centrifuged at $400 \times g$ for $10 \mathrm{~min}$ ). Five hundred $\mu \mathrm{l}$ of FXCycle PI/RNase staining solution was added to the cell pellets (approximately $1 \times 10^{6} / \mathrm{ml}$ spermatozoa) and after vortexing the samples were incubated for $30 \mathrm{~min}$ at room temperature in the dark before flow cytometric analyses.

\section{Flow cytometry}

We measured the DNA quantity expressed as PI fluorescence intensity with a Beckman Coulter FC500 flow cytometer, equipped with a $488 \mathrm{~nm} 20 \mathrm{~mW}$ argon ion laser. PI fluorescence was detected on an FL3 detector (655 nm LP) in linear mode. Sperm head orientation was not taken into consideration as our benchtop flow cytometer was not equipped with such an orienting device. Doublet discrimination was done according to the suggestions of the manufacturer (Beckman Coulter). Five thousand events per sample were recorded and scatter and fluorescence intensities were stored in list mode files. The flow cytometer was calibrated daily with FlowCheck fluorospheres (6605359, Beckman Coulter); moreover, in order to monitor random drift in fluorescence intensities between samples, every sample contained $10 \mu 1$ FlowSet fluorospheres (6607007, Beckman Coulter) serving as internal control.

\section{Analysis}

In Experiment 1, one-parameter PI fluorescence intensity histograms were drawn and individual histogram profiles were compared with the KolmogorovSmirnov option in the CXP Analysis software (Beckman Coulter) of the cytometer. This analysis assesses the difference between two populations and shows the maximum difference between two cumulative frequency distributions expressed as Dmax value (Young, 1977; Watson, 2001). Dmax values were calculated for paired histograms (three bulls, three repeats: $\mathrm{n}=36$ pairs) and these values were checked for normality using Lilliefors test and descriptive statistics were established with Statistica for Windows (version 8, Statsoft Inc.).

In Experiment 2, the histogram profiles (Fig. 1) of the carrier bulls were compared to the control bull using the Kolmogorov-Smirnov test as described above. The threshold Dmax value to differentiate healthy and possibly defective animals was derived from the descriptive statistics in Experiment 1 and was calculated as mean +2 SD (Indrayan, 2012). 



Fig. 1. DNA histogram overlays of the carrier bulls (B-E; white histograms) and the control bull (A; grey). X-axis shows PI fluorescence, expressed on a linear, 1023-channel scale

\section{Results}

\section{Experiment 1}

Dmax values of the paired histograms are shown in Table 1. The Kolmogorov-Smirnov test revealed significant differences between bulls or even between repeated measurements of the same individual $(\mathrm{P}<0.05)$ with the exception of bull 2 where the repeated measurements were not significantly different. However, since the Kolmogorov-Smirnov test is reported to be oversensitive (Parikh et al., 1999; Lampariello, 2000) we did not consider this as a flaw of the data analysis approach.

Dmax values showed normal distribution $(\mathrm{P}>0.2$, Lilliefors test $)$ and the descriptive statistics were as follow: mean: 0.087; SD: 0.037; variance: 0.001; minimum: 0.018; maximum: 0.155. The calculated Dmax threshold value was 0.161 (calculated as mean $+2 \mathrm{SD}$ ). 
Table 1

Matrix of Dmax values of paired histograms of the three healthy bulls measured in three repeats

\begin{tabular}{lccccccccc}
\hline Sample & 11 & 12 & 13 & 21 & 22 & 23 & 31 & 32 & 33 \\
\hline 11 & 0 & 0.059 & 0.117 & 0.086 & 0.084 & 0.0868 & 0.128 & 0.074 & 0.155 \\
12 & & 0 & 0.061 & 0.119 & 0.107 & 0.119 & 0.081 & 0.091 & 0.106 \\
13 & & & 0 & 0.136 & 0.119 & 0.133 & 0.059 & 0.100 & 0.072 \\
21 & & & & 0 & $\mathbf{0 . 0 2 6}$ & $\mathbf{0 . 0 2 1}$ & 0.106 & 0.038 & 0.130 \\
22 & & & & & 0 & $\mathbf{0 . 0 1 8}$ & 0.086 & $\mathbf{0 . 0 2 7}$ & 0.105 \\
23 & & & & & & 0 & 0.103 & 0.035 & 0.123 \\
31 & & & & & & & 0 & 0.079 & 0.035 \\
32 & & & & & & & & 0 & 0.099 \\
33 & & & & & & & & & 0 \\
\hline
\end{tabular}

Sample codes mean: bull-repeat (i.e. 11 means Bull 1 repeat 1). Dmax values not significant at $\mathrm{P}<$ 0.05 are in bold italics

\section{Experiment 2}

The histogram profiles (Fig. 1) of the carrier bulls differed significantly $(\mathrm{P}<0.01)$ from the control bull $(\mathrm{A})$ and the Dmax values were as follow: bull $\mathrm{A}$ vs. B: 0.245; A vs. C: 0.128; A vs. D: 0.416; A vs. E: 0.166. With the exception of bull $\mathrm{C}$, every carrier bull showed higher Dmax value than the threshold value established in Experiment 1. This can be explained as in that case smaller chromosomes (chromosomes 20 and 24) were involved, so probably only a very small amount of DNA was missing or added in the affected sperm cells.

\section{Discussion}

In our opinion this flow cytometric approach has several advantages. The fluorescent labelling kit is easy to use, does not require excessive sample preparation, quick, and the fluorochrome can be analysed with the standard laser line and optics of every benchtop flow cytometer. The Kolmogorov-Smirnov option is available in the software of most flow cytometer brands, therefore no additional software purchase is needed. Individual bulls or even insemination doses can be evaluated quickly, so the method can be applied to test the animal even if he is not physically present (like in the case of semen import). We suggest that every laboratory should establish its threshold values following the study design described above as flow cytometer instruments with different optical settings may result in different Dmax values; moreover, different cattle breeds (due to Y chromosome polymorphisms, for example) may have different DNA histogram profiles. The test fits into the laboratory routine where flow cytometry is applied for semen quality control, and this analysis should be carried out only once in the lifetime of a bull. 


\section{Acknowledgement} 109039).

This study was supported by the National Scientific Research Fund (OTKA K-

\section{References}

Amann, R. P. and DeJarnette, J. M. (2012): Impact of genomic selection of AI dairy sires on their likely utilization and methods to estimate fertility: a paradigm shift. Theriogenology 77, 795-817.

Amann, R. P. and Hammerstedt, R. H. (1993): In vitro evaluation of sperm quality: an opinion. J. Androl. 14, 397-406.

Andersson, M., Aalto, J. and Gustavsson, I. (1992): Embryo quality and andrological study of two subfertile bulls versus five control bulls with normal fertility. Theriogenology 38, 623-631.

Christensen, K. and Pedersen, J. O. (1990): Chromosome C-band polymorphism in relation to fertility in boars of the Duroc breed. Hereditas 113, 183-187.

Dadoune, J-P. (1995): The nuclear status of human sperm cells. Micron 26, 323-345.

Dixon, S. C., Miller, N. G. A., Carter, N. P. and Tucker, E. M. (1992): Bivariate flow cytometry of farm animal chromosomes: a potential tool for gene mapping. Anim. Genet. 23, 203-210.

Dolezel, J. and Bartos, J. (2005): Plant DNA flow cytometry and estimation of nuclear genome size. Ann. Bot. 95, 99-110.

Ducos, A., Revay, T., Kovacs, A., Hidas, A., Pinton, A., Bonnet-Garnier, A., Molteni, L., Slota, E., Switonski, M., Arruga, M. V., van Haeringen, W. A., Nicolae, I., Chaves, R., GuedesPinto, H., Andersson, M. and Iannuzzi, L. (2008): Cytogenetic screening of livestock populations in Europe: an overview. Cytogenet. Genome Res. 120, 26-41.

Evenson, D. P. (1999): Loss of livestock breeding efficiency due to uncompensable sperm nuclear defects. Reprod. Fert. Dev. 11, 1-15.

Garner, D. L. (2001): Sex-sorting mammalian sperm: concept to application in animals. J. Androl. 22, 519-526.

Givan, A. L. (2001): Flow Cytometry: First Principles. Wiley-Liss, Inc., 273 pp.

Gledhill, B. L., Lake, S., Steinmetz, L. L., Gray, J. W., Crawford, J. R., Dean, P. N. and Van Dilla, M. A. (1976): Flow microfluorometric analysis of sperm DNA content: effect of cell shape on the fluorescence distribution. J. Cell Physiol. 87, 367-375.

Hossain, M. S., Johannisson, A., Wallgren, M., Nagy, S., Siqueira, A. P. and Rodriguez-Martinez, H. (2011): Flow cytometry for the assessment of animal sperm integrity and functionality: state of the art. Asian J. Androl. 13, 406-419.

Indrayan, A. (2012): Medical Biostatistics. Chapman \& Hall/CRC Press, 1024 pp.

Lampariello, F. (2000): On the use of the Kolmogorov-Smirnov statistical test for immunofluorescence histogram comparison. Cytometry 39, 179-188.

Langford, C. F., Fischer, P. E., Binns, M. M., Holmes, N. G. and Carter, N. P. (1996): Chromosome-specific paints from a high-resolution flow karyotype of the dog. Chromosome Res. 4, 115-123.

Larsen, J., Christensen, K., Larsen, J., Jensen, P., Gustavsson, I. and Christensen, I. (2004): High resolution DNA flow cytometry of boar sperm cells in identification of boars carrying cytogenic aberrations. Theriogenology 62, 501-511.

Lewalski, H., Otto, F. J., Kranert, T., Glahn-Luft, B. and Wassmuth, R. (1991): Analysis of the $1 / 20$ translocation in ram spermatozoa by flow cytometry. Genet. Sel. Evol. 23, Suppl. $152-156$. 
Lewalski, H., Otto, F. J., Kranert, T. and Wassmuth, R. (1993): Flow cytometric detection of unbalanced ram spermatozoa from heterozygous 1;20 translocation carriers. Cytogenet. Cell Genet. 64, 286-291.

Matsson, P., Annerén, G. and Gustavsson, I. (1986): Flow cytometric karyotyping of mammals, using blood lymphocytes: Detection and analysis of chromosomal abnormalities. Hereditas 104, 49-54.

Meistrich, M. L., Göhde, W., White, R. A. and Schumann, J. (1978): Resolution of X and Y spermatids by pulse cytophotometry. Nature 274, 821-823.

Morrell, J. M. and Rodriguez-Martinez, H. (2009): Biomimetic techniques for improving sperm quality in animal breeding: a review. Open Androl. J. 1, 1-9.

Parikh, H. H., Li, W. C. and Ramanathan, M. (1999): Evaluation of an alternative to the Kolmogorov-Smirnov test for flow cytometric histogram comparisons. J. Immunol. Methods 229, 97-105.

Petrie, A. and Watson, P. (1999): Statistics for Veterinary and Animal Science. Blackwell Science Ltd. $243 \mathrm{pp}$.

Revay, T., Kopp, C., Flyckt, A., Taponen, J., Ijäs, R., Nagy, Sz., Kovacs, A., Rens. W., Rath, D., Hidas, A., Taylor, J. F. and Andersson, M. (2010): Diploid spermatozoa caused by failure of the second meiotic division in a bull. Theriogenology 73, 421-429.

Revay, T., Nagy, Sz., Kopp, C., Flyckt, A., Rens, W., Rath, D., Hidas, A., Kovacs, A., Johannisson, A., Rodriguez-Martinez, H. and Andersson, M. (2009): Macrocephaly in bull spermatozoa is associated with nuclear vacuoles, diploidy and alteration of chromatin condensation. Cytogenet. Genome Res. 126, 202-209.

Sakkas, D., Mariethoz, E., Manicardi, G., Bizarro, D., Bianchi, P. G. and Bianchi, U. (1999): Origin of DNA damage in human spermatozoa. Rev. Reprod. 4, 31-37.

Switonski, M., Andersson, M., Nowacka-Woszuk, J., Szczerbal, I., Sosnowski, J., Kopp, C., Cernohorska, H. and Rubes, J. (2008): Identification of a new reciprocal translocation in an AI bull by synaptonemal complex analysis, followed by chromosome painting. Cytogenet. Genome Res. 121, 245-248.

van den Engh, G. J., Trask, B. J., Gray, J. W., Langlois, R. G. and Yu, L.-C. (1985): Preparation and bivariate analysis of suspensions of human chromosomes. Cytometry 6, 92-100.

Venhoranta, H., Pausch, H., Wysocki, M., Szczerbal, I., Hänninen, R., Taponen, J., Uimari, P., Flisikowski, K., Lohi, H., Fries, R., Switonski, M. and Andersson, M. (2013): Ectopic KIT copy number variation underlies impaired migration of primordial germ cells associated with gonadal hypoplasia in cattle (Bos taurus). PLoS One 26, e75659.

Watson, J. V. (2001): Proof without prejudice revisited: immunofluorescence histogram analysis using cumulative frequency subtraction plus ratio analysis of means. Cytometry 43, 55-68.

Young, I. T. (1977): Proof without prejudice: use of the Kolmogorov-Smirnov test for the analysis of histograms from flow systems and other sources. J. Histochem. Cytochem. 25, 935-941. 